\title{
Apical transthoracic Doppler echocardiography can be useful for analysis of postoperative early function of the left internal thoracic artery
}

\author{
Mitsumasa Hata, MD, a Jai S. Raman, FRACS, ${ }^{a}$ Motomi Shiono, MD, ${ }^{\mathrm{b}}$ Nanao Negishi, MD, ${ }^{\mathrm{b}}$ Yukiyasu Sezai, MD, \\ Elizabeth D. Croce, MA, CMI, ${ }^{a}$ and Brian F. Buxton, FRACS, ${ }^{a}$ Melbourne, Australia, and Tokyo, Japan
}

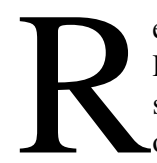

ecent studies have demonstrated that transthoracic Doppler echocardiography, via either a parasternal or supraclavicular approach, can reliably assess the postoperative early patency of the left internal thoracic artery (LITA) after grafting. ${ }^{1,2}$ However, the Doppler waveform along the proximal LITA shows a different pattern from that of the distal LITA because of the effect of blood pulsatility from the subclavian artery. Therefore, it may be difficult to assess accurately whether the graft is functionally patent. We consider it important to evaluate the Doppler waveform along the LITA just proximal to

\footnotetext{
From the Department of Cardiac Surgery, ${ }^{\text {a }}$ Austin \& Repatriation Medical Centre, University of Melbourne, Melbourne, Australia, and the Second Department of Surgery, ${ }^{\mathrm{b}}$ Nihon University School of Medicine, Tokyo, Japan.

Received for publication May 24, 2001; accepted for publication July 11, 2001.

Address for reprints: Mitsumasa Hata, MD, PhD, The Department of Cardiac Surgery, Austin \& Repatriation Medical Centre, Austin Campus, Studley Rd, Heidelberg, Victoria 3084, Australia (E-mail: cvshata@aol.com).

J Thorac Cardiovasc Surg 2002;123:385-7

Copyright (C) 2002 by The American Association for Thoracic Surgery

$0022-5223 / 2002 \$ 35.00+0 \quad \mathbf{1 2 / 5 4 / 1 1 8 6 8 0}$

doi: $10.1067 / \mathrm{mtc} .2002 .118680$
}

the anastomosis with the left anterior descending coronary artery (LAD), because the distal portion of the LITA is the most sensitive and is easily affected by vasospasm. ${ }^{3}$ The aim of this study was to evaluate the efficacy of transthoracic Doppler echocardiography, using apical views, for assessing the early postoperative graft function of the LITA grafted to the LAD.

\section{Methods}

Sixty-six patients who underwent coronary artery bypass grafting, including 10 having off-pump bypass grafting, were studied. The mean age of the patients was $65.2 \pm 7.1$ years (mean \pm SD) and the average number of grafts per patient was $3.12 \pm 0.67$. We evaluated postoperative LITA function either immediately after surgery or during the first postoperative day (POD 1) with transthoracic pulsed Doppler echocardiography using an Acuson C256 machine (Acuson Corp, Mountain View, Calif) equipped with a $7-\mathrm{MHz}$ transducer. The patient was rolled about $45^{\circ}$ toward the left side. First, a left anterior oblique view was visualized by color Doppler imaging by means of an apical approach (Figure 1). Next, the probe was rotated about $45^{\circ}$ toward the patient's left side. The LAD was then located along the interventricular groove. Finally, the point of anastomosis between the LITA and the LAD was detected by tipping the probe slightly upward (Figure 2, top). The Doppler waveform in the distal portion of the grafted LITA has a biphasic velocity pattern with a higher mid-diastolic and lower 


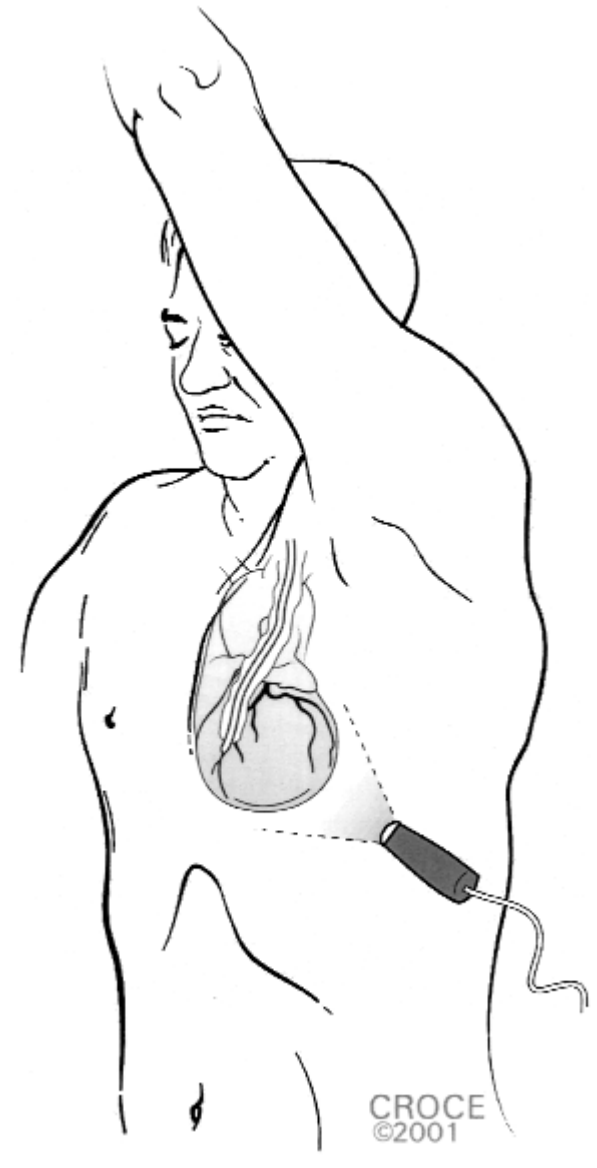

Figure 1. Schematic drawing of the patient and echo probe position.

antegrade component at end-systole (Figure 2, bottom). The LITA diameter, peak and mean diastolic velocity, velocity time integral, and diastolic/systolic velocity ratios (D/S) were measured with online calipers and averaged over 3 cardiac cycles.

\section{Results}

Echocardiogram. The LITA was effectively detected and good-quality Doppler waveforms were obtained in all patients. The LITA diameter was significantly enlarged in the first month after surgery compared with POD 1 (mean \pm SD; $1.90 \pm 0.33$ vs $1.72 \pm$ $0.72 \mathrm{~mm} ; P<.05$, paired $t$ test). The peak and mean diastolic velocities on POD 1 were $0.24 \pm 0.02$ and $0.17 \pm 0.02 \mathrm{~m} / \mathrm{s}$, respectively, and the peak and mean D/S ratios on POD 1 were $1.64 \pm$ 0.02 and $1.63 \pm 0.01$, respectively. These results were unchanged 1 month postoperatively. The velocity time integral was also significantly increased in the first month after surgery compared with on POD $1(12.1 \pm 2.7$ vs $10.6 \pm 2.2 \mathrm{~cm} ; P<.05)$.

Angiogram. On the basis of the angiographic results at 1 month postoperatively, the patients were divided into 2 groups. Group I ( $n$ = 63) included patients who had no problems around the LITA anastomosis, whereas group II $(n=3)$ consisted of 2 patients with $90 \%$ stenosis at the point of anastomosis and 1 patient whose anas-

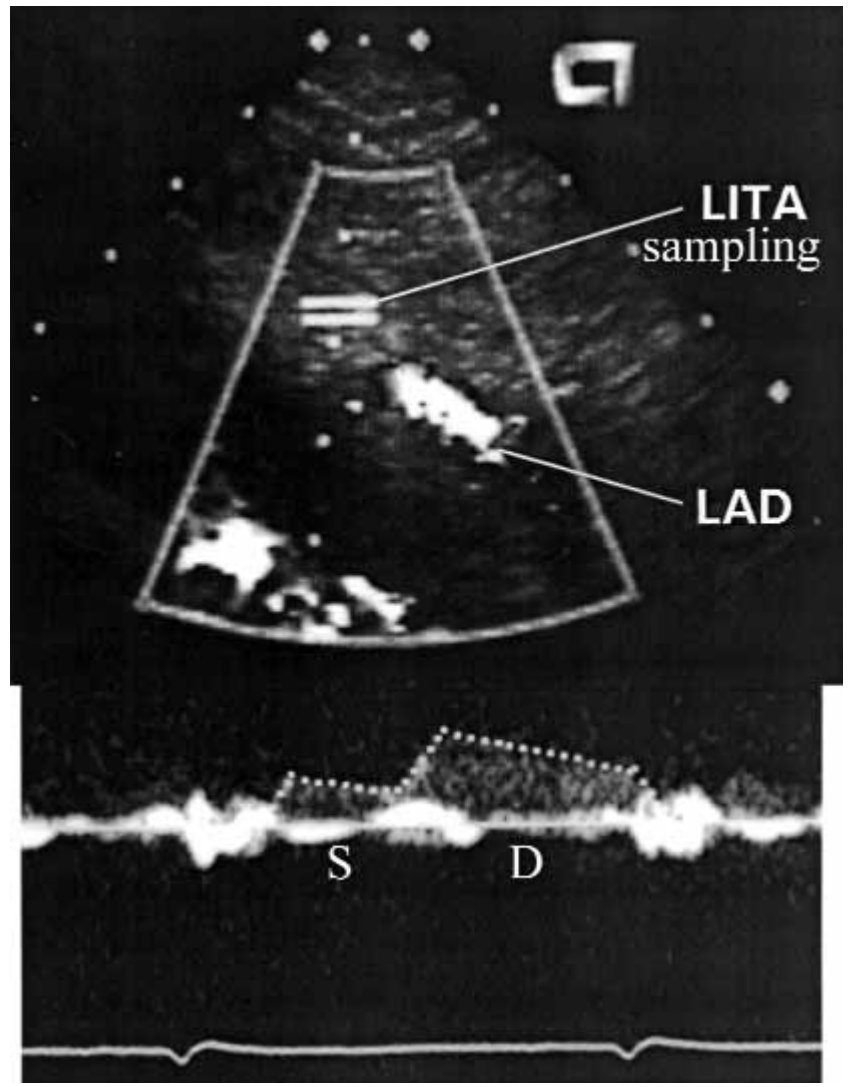

Figure 2. Doppler spectral trace of the distal portion of the left internal thoracic artery (LITA) and its flow velocity pattern showing LITA sampling at a point just proximal to the anastomosis (top) and LITA flow velocity waveform (bottom). LAD, Left anterior descending artery; $S$, systolic wave; $D$, diastolic wave.

tomosis demonstrated reversed flow from the native LAD. In group II, the average peak and mean diastolic velocities were 0.17 \pm 0.13 and $0.13 \pm 0.11 \mathrm{~m} / \mathrm{s}$, respectively, and the peak and mean $\mathrm{D} / \mathrm{S}$ ratios on POD 1 were $0.98 \pm 0.12$ and $0.87 \pm 0.10$, respectively. These results were significantly lower than those of group I $(0.23 \pm 0.03$ and $0.16 \pm 0.02 \mathrm{~m} / \mathrm{s}, P=.003$, and $1.67 \pm 0.24$ and $1.65 \pm 0.21, P=.004$ : Mann-Whitney $U$ test). LITA Doppler wave with $\mathrm{D} / \mathrm{S}$ of more than 1.0 was associated with good angiographic findings.

\section{Discussion}

The early postoperative graft flow reserve of the LITA may be insufficient at times because of vasospasm or the effects of cardiopulmonary bypass. ${ }^{4}$ Furthermore, the graft patency within the first few weeks of surgery is also dependent on anastomotic technique, and occlusion or stenosis may be caused by technical problems. Therefore, we consider the routine evaluation of the LITA Doppler waveform along the portion proximal to the anastomosis to the LAD early in the postoperative period to be an essential part of the postoperative assessment of LITA grafts.

A previous report described a lower peak D/S ratio in a Doppler echocardiographic study because of a stenosis of the LITA anasto- 
mosed to the LAD. ${ }^{1}$ In our patients, early conduit or anastomotic malfunction was suggested in 3 cases because the $\mathrm{D} / \mathrm{S}$ ratios were less than 1.0. Angiography 1 month postoperatively demonstrated anastomotic stenosis in 2 cases and competitive LITA flow from the native $\mathrm{LAD}$ in 1 case. The latter patient was observed with the expectation of LITA remodeling. $\mathrm{We}^{5}$ previously reported a case in which an early postoperative LITA string sign resulting from flow reversal disappeared spontaneously. The patency of the vessel was markedly improved on the 1-year postoperative angiogram. ${ }^{5}$ In this study, the postoperative average diameter of the LITAs was significantly increased at 1 month. The presence of an abnormal waveform as seen in the apical view of the LITA Doppler study was correlated with angiographic abnormality. In contrast, a LITA with a D/S ratio of more than 1.0 and an enlarged diameter is likely to have excellent LITA function.

\section{Conclusion}

The Doppler apical approach may offer a noninvasive and repeatable method of evaluating LITA graft function in the immediate postoperative period. This technique is economical and avoids complications of angiography such as bleeding and infection. We recommend performing postoperative LITA graft angiography if the LITA Doppler findings show the D/S ratio to be less than 1.0.

\section{References}

1. Calafiore AM, Gallina S, Iaco A, Teodori G, Iovino T, Giammarco GD, et al. Minimally invasive mammary artery Doppler flow velocity evaluation in minimally invasive coronary operations. Ann Thorac Surg. 1998;66:1236-41.

2. Pezzano A, Fusco R, Child M, Riccobono S, Milazzo A, Recalcati F, et al. Assessment of left internal mammary artery grafts using dipyridamole Doppler echocardiography. Am J Cardiol. 1997;80:1603-6.

3. He GW, Acuff TE, Yang CQ, Tyan WH, Mack MJ. Middle and proximal sections of the human internal mammary artery are not "passive conduits." J Thorac Cardiovasc Surg. 1994;108:741-6.

4. De Paulis R, Tomai F, Gaspardone A, Colagrande L, Nardi P, Ghini A, et al. Coronary flow reserve early and late after minimally invasive coronary artery bypass grafting in patients with totally occluded left anterior descending coronary artery. $J$ Thorac Cardiovasc Surg. 1999;118:604-9.

5. Hata M, Shiono M, Orime Y, Yagi S, Kimura S, Sezai Y, et al. Spontaneous recanalization of postoperative severe graft stenosis. What is the cause and prognosis of the "string sign" in the internal thoracic artery? Ann Thorac Cardiovasc Surg. 1999;5:52-5. 